\title{
RF MEMS Impedance Tuners for 6-24 GHz Applications
}

\author{
Tauno Vähä-Heikkilä, ${ }^{1,2}$ Koen Van Caekenberghe, ${ }^{2}$ Jussi Varis, ${ }^{1}$ Jussi Tuovinen, ${ }^{1}$ \\ Gabriel M. Rebeiz ${ }^{2,3}$ \\ ${ }^{1}$ MilliLab, VTT Technical Research Centre of Finland, P.O. BOX 1000, 02044 VTT, Finland \\ ${ }^{2}$ Department of Electrical Engineering and Computer Science, The University of Michigan, \\ Ann Arbor, MI 48109-2122 \\ ${ }^{3}$ Department of Electrical and Computer Engineering, University of California, San Diego, \\ La Jolla, CA 92037
}

Received 17 May 2006 ; accepted 15 December 2006

\begin{abstract}
RF MEMS tuners with wide impedance coverage have been developed for 6$24 \mathrm{GHz}$ noise parameter and load-pull measurement systems. The tuners are based on triple-, double-, and single-stub topologies loaded with switched MEMS capacitors. Several designs are presented, and they use 10-13 switched MEMS capacitors to produce 1024$8192\left(2^{10}-2^{13}\right)$ different impedances. The measured impedance coverage agrees well with simulations and it is the widest ever measured impedance coverage from any planar tuner to-date. () 2007 Wiley Periodicals, Inc. Int J RF and Microwave CAE 17: 265-278, 2007.
\end{abstract}

Keywords: RF MEMS; impedance tuner; noise parameters; load-pull; matching network; antenna tuner

\section{INTRODUCTION}

Impedance tuners are commonly used in both load-pull and noise parameter measurements of transistors at microwave and millimeter-wave frequencies, e.g [1-3]. Typically, these are mechanical devices with either coaxial or waveguide structures, and use motors for automatic control. Tuners are also made using diodes and transistors, but these designs are lossy and result in a limited impedance coverage $[4,5]$. Also, they add electronic noise which makes accurate noise measurements more challenging. RF MEMS impedance tuners with low loss and large impedance coverage are therefore desirable to increase measure-

Correspondence to: T. Vähä-Heikkilä; e-mail: tauno.vahaheikkila@vtt.fi.

DOI 10.1002/mmce. 20220

Published online 26 March 2007 in Wiley InterScience (www. interscience.wiley.com). ment automation and accuracy. Also, MEMSbased impedance tuners are small enough to be mounted inside an on-wafer probe. An impedance tuner can either be of the transmission or reflection-type (Fig. 1) design, and typical impedance tuners are based either on double-stub $[6,7]$ or triple-stub topologies $[8,9]$. The stub topologies are not ideal for power amplifier applications since they result in a higher loss compared with loadedline tuners introduced by Vähä-Heikkilä and Rebeiz in $[10,11]$. Also, Shen and Barker have presented a distributed type double slug impedance tuner with low loss [12]. Still, the stub-based tuners result in excellent impedance coverage over a wide frequency range as well as high voltage standing wave ratios (VSWR), and are suitable to be used as noise parameter or load-pull impedance tuners.

In this work, impedance tuners based on switched MEMS capacitors are presented. The goal is not only 


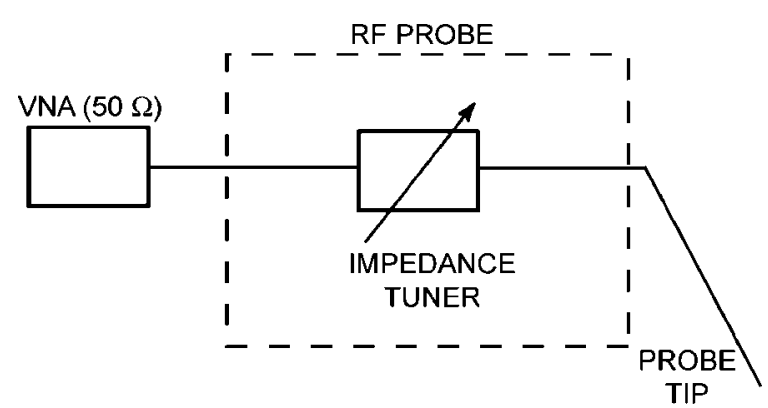

(a)

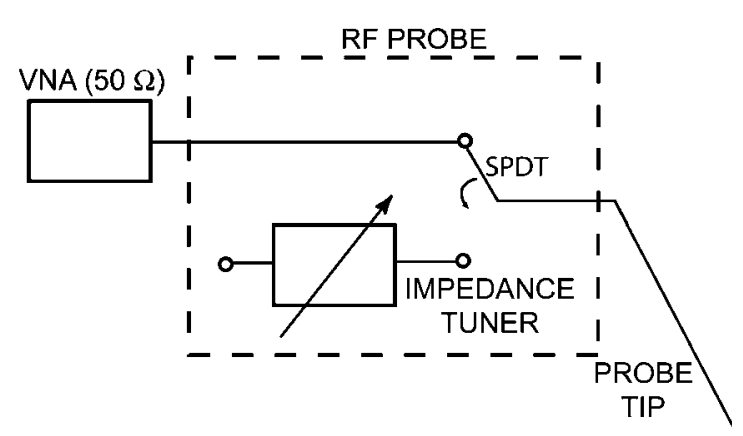

(b)

Figure 1. (a) Transmission and (b) reflection-type impedance tuner inside an RF probe used in on-wafer measurements.

to achieve a wide impedance coverage, but also to achieve this over a wide frequency range. This is done using a novel idea based on changing the electrical length and separation between the tuning stubs with the switched capacitor approach. The impedance and electrical length of the stub are also changed using MEMS switched capacitors. This method results in $2^{N}$ different impedances over a wide frequency range for a stub circuit loaded with $N$ different switched capacitors.

\section{TUNER DESIGN}

An RF MEMS switch in series with a fixed metalair-metal (MAM) capacitor is the basic building block of the stub-based tuners. There are several parameters which affect the impedance coverage of impedance tuners: the number and capacitance values of the switched MEMS capacitors have the most important effect on the tuning range and bandwidth. Other selectable parameters are the spacing of the switched capacitors, the transmission-line ( $\mathrm{t}$-line) properties $\left(Z_{0}, \varepsilon_{\text {reff }}\right)$, the distance between the stubs, and the lengths of the stubs.

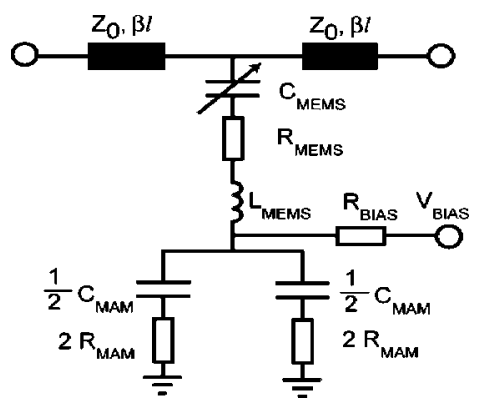

Figure 2. Equationuivalent circuit of a switched MEMS capacitor (unit cell in tuner design).
The single-, double-, and triple-stub designs are optimized using Agilent ADS (Advanced Design System 2002, Agilent Technologies, Santa Clara, $\mathrm{CA}, 2002)$ to obtain as large a tuning range and bandwidth as possible with the minimum number of switched MEMS capacitors. We have not found a closed-form design technique since there are many design parameters for impedance tuners. Some design insights are given later in the paper. The equivalent circuit of the switched MEMS capacitor is shown in Figure 2, and the component values are presented in Table I. The up-state capacitance of the switched capacitor is determined mostly by the upstate capacitance of the MEMS switch, and the down-state capacitance is determined by the two MAM capacitors [11].

Figure 3 shows a fabricated switched MEMS capacitor on a coplanar waveguide (CPW) t-line on a glass substrate (Corning 7040). The fabrication process is based on standard surface MEMS techniques and is described in Ref. 13. The dimensions of the gold MEMS switch are $280 \mu \mathrm{m} \times 80 \mu \mathrm{m} \times 0.8 \mu \mathrm{m}$, and it is suspended $1.1 \mu \mathrm{m}$ above the t-line. A 3500 $\AA$ silicon nitride layer was used as a dielectric interlayer. The circuit is electroplated to $3-\mu \mathrm{m}$ thickness (except the MEMS bridges) to reduce the t-line and MAM capacitor loss. $\mathrm{SiCr}$ bias lines with resistance of $700 \Omega$ /square are used for actuating the MEMS switches. The measured pull-down voltage is $15-17$ $\mathrm{V}$, and a bipolar actuation voltage of $\pm 35 \mathrm{~V}$ was used for obtaining an excellent metal-to-dielectric contact in the down-state position.

As seen in Table I, the measured capacitance ratio of the RF MEMS switch is only 8:1 because of its low height and the thick silicon-nitride layer. The total up-state and down-state capacitances of the switched capacitor are $C_{\mathrm{U}}=82.2 \mathrm{fF}$ and $C_{\mathrm{D}}=398 \mathrm{fF}$, respectively, resulting in a capacitance ratio of $4.9: 1$. The 
TABLE I. Measured t-Line Properties from the trl Calibration and Fitted Values for the Switched MEMS Capacitor

\begin{tabular}{lc}
\hline$\varepsilon_{\mathrm{r}}$ & \\
$Z_{0}(\Omega)(100 / 100 / 100 \mu \mathrm{m})$ & 86.6 \\
$\varepsilon_{\text {reff }}$ & 2.72 \\
$\alpha(\mathrm{dB} / \mathrm{cm}), 10 / 20 \mathrm{GHz}$ & $0.35 / 0.52$ \\
$C_{\text {MEMS }}$ up-state $(\mathrm{fF})$ & 91 \\
$C_{\text {MEMS down-state }(\mathrm{fF})}$ & 750 \\
$R_{\text {BIAS }}(\mathrm{k} \Omega)$ & $>3$ \\
$L_{\text {MEMS }}(\mathrm{pH})$ & 9.5 \\
$R_{\text {MEMS }}+R_{\text {MAM }}(\Omega)$ & 0.6 \\
$C_{\text {MAM }}(\mathrm{fF})$ & 850 \\
\hline
\end{tabular}

quality factor of the switched MEMS capacitor is calculated using $Q=\left(2 \pi f C\left(R_{\mathrm{MEMS}}+R_{\mathrm{MAM}}\right)\right)^{-1}$, and at $12 \mathrm{GHz}$ results in an up and down-state values of $Q_{\mathrm{U}}$ $=269\left(C_{\mathrm{U}}=82.2 \mathrm{fF}, X=-j 161 \Omega\right)$ and $Q_{\mathrm{D}}=55$ $\left(C_{\mathrm{D}}=398 \mathrm{fF}, X=-j 33.3 \Omega\right)$, respectively. Table II summarizes the properties of the entire unit cell of Figure 3 . The unit cell has $31^{\circ}$ phase change between its up and down-states at $12 \mathrm{GHz}$.

The reconfigurable triple-, double-, and singlestub impedance tuners were optimized to have 10-13 identical switched MEMS capacitors (S1-S13). The number of switched capacitors $(N)$ has great effect to the impedance coverage of the tuners. By using a larger number of switched capacitors better impedance coverage can be achieved at the cost of a more complicated control system and higher circuit loss.

The switched capacitors were used for tuning the electrical lengths of the stubs and also the separation between them. Spacing between the stubs is $3.0 \mathrm{~mm}$ for the double- and triple-stub designs (Figs. 4-7). It should be noted that a small capacitance ratio does not result in a large tuning range at the lower frequencies, but on the other hand, a high

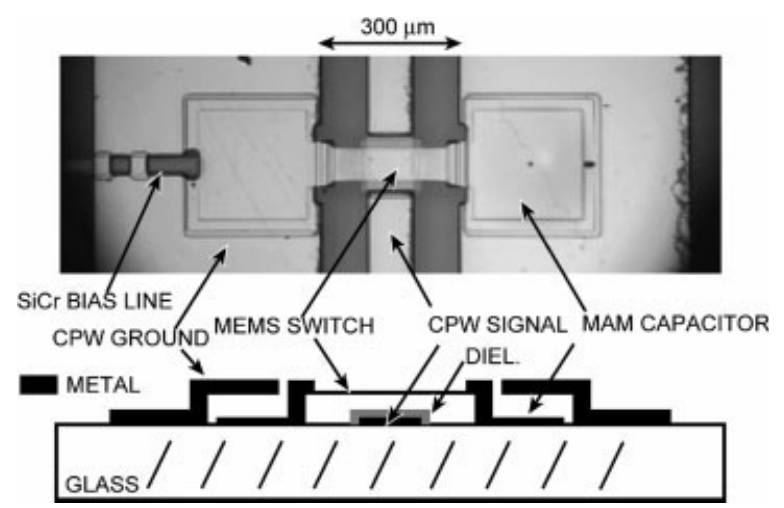

Figure 3. Picture and cross-sectional view of a switched MEMS capacitor unit cell. capacitance ratio causes a short circuit at higher frequencies. Therefore, the circuits were optimized with a large number of simulations in ADS, and the best capacitance ratio was found to be between 4 and 10 .

There is truly a large number of circuit combinations which can offer a wide frequency coverage and wide tuning range, and in this article, we will present four representative circuits based on triple- (Figs. 4 and 5), double- (Fig. 6), and single-stub (Fig. 7) designs. Notice that the double-stub design is physically rather small, and owes its wide tuning range to the use of three-switched capacitors between the stubs.

\section{CIRCUIT MODEL}

An accurate circuit model of the tuner is very important in predicting the impedance coverage and behavior over a wide frequency range. Also, the tuners have 10-13-switched capacitors producing 10248192 different impedances making it time consuming to measure all the different combinations. The circuit models were developed by first measuring several switched MEMS capacitors both as single elements and as elements in a distributed (loaded-line) network as in Ref 11, and deriving the equivalent circuit of the unit-cell switched capacitor (Fig. 2 and Tables I and II). To get accurate models for the T-junctions, they were simulated with the Sonnet (Sonnet, ver. 8.52, Sonner Software, Syracuse, NY, 1986-2001) full wave EM simulator as three-port elements, and also having air bridges crossing each arm. The unit cell, the Sonnet models of the T junctions, and the $\mathrm{t}$ line characteristics were all used in Agilent ADS for predicting the response of the whole network under different switch combinations. The accuracy of the model is clearly seen with a comparison between the simulated and measured S-parameters for the tripleand double-stub tuners in Figures 8 and 9. The models agree for all switch combinations which were

TABLE II. Properties of the Unit Cell

\begin{tabular}{lc}
\hline Length $(\mu \mathrm{m})$ & 480 \\
\hline$Z_{0}(\Omega)$ & 86.2 \\
$Z_{\mathrm{U}}(\Omega)$ & 45 \\
$Z_{\mathrm{D}}(\Omega)$ & 23 \\
$\phi_{\mathrm{U}}($ degree $)$ at $12 \mathrm{GHz}$ & -22.3 \\
$\phi_{\mathrm{D}}($ degree $)$ at $12 \mathrm{GHz}$ & -53.2 \\
$Q_{\mathrm{U}}$ at $12 \mathrm{GHz}$ & 269 \\
$Q_{\mathrm{D}}$ at $12 \mathrm{GHz}$ & 55 \\
\hline
\end{tabular}




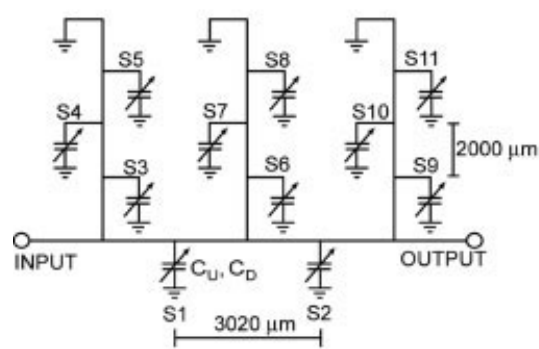

(a)

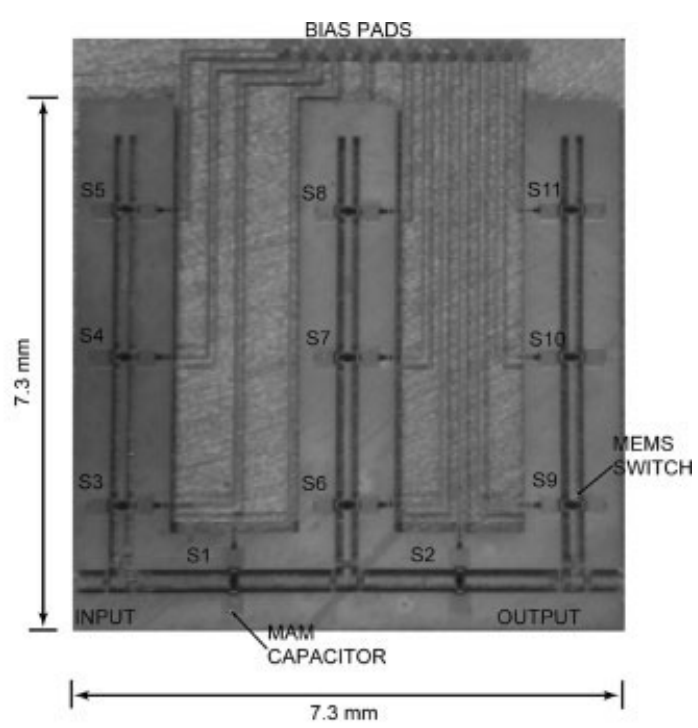

(b)

Figure 4. (a) Circuit diagram and (b) picture of the 6-20 GHz reconfigurable triple-stub RF MEMS impedance tuner with 11-switched MEMS capacitors (S1-S11). Notice that the stubs are short circuited.

tested, but only two representative conditions are shown in Figures 8 and 9.

\section{IMPEDANCE COVERAGE}

\section{A. Triple-Stub Tuner with 11-Switched Capacitors}

The measured $(160)$ and simulated $\left(2^{11}=2048\right)$ impedance points of the reconfigurable triple-stub tuner are presented in Figure 10 at 6-20 GHz. In this case, a $50 \Omega$ load was placed at the output port, and the input reflection coefficients were measured with different switches actuated into the down-state position. Due to the number of points in the measurement setup, it is hard to show a 1:1 mapping between the measured and simulated data, but they agree quite well with each other (see also Figures 8 and 9). It can be seen that the obtained impedance coverage is good for noise-parameter or load-pull measurements. There is some discrepancy at $20 \mathrm{GHz}$, and this occurs when the triple-stub network is electrically quite large and the CPW lines are starting to radiate, which is not modeled by Agilent ADS, and full 3D EM simulations would be needed for the whole network. We have indeed modeled the CPW $\mathrm{T}$-junctions alone and have seen radiation effects and loss occurring at $20 \mathrm{GHz}$.

The network can also be used for matching a lowimpedance load $(10 \Omega)$ at virtually all frequencies between 6 and $20 \mathrm{GHz}$, but as will be seen in Section $\mathrm{V}$, the triple-stub tuner results in higher loss compared to other designs [9].

The triple-stub tuner with 11 switches can also be used in a reflection-mode with open or short-circuit termination at the output port (Fig. 1) for obtaining wide impedance coverage (Fig. 11). This is useful in noise parameter measurements, and in this case, an important characteristic is to get a near-circular impedance locus on the Smith chart [14].

\section{B. Triple-Stub Tuner with 13-Switched Capacitors}

The triple-stub tuner was also optimized for 13switched capacitors. Two additional switched capacitors were placed between the stubs to result in a higher tuning (2-bit instead of 1-bit) range for the electrical distance between the stubs. This tuner results in 8192 $\left(2^{13}\right)$ different impedances, and its measured (160 points) and simulated impedance coverage with a 50 $\Omega$ load at the output port are shown in Figure 12. Also, the simulated impedance coverage with the output terminated with an open circuit is shown in Figure 13. It is seen that the impedance coverage with the $50 \Omega$ load is not much wider compared to the design with 11-switched capacitors, but better impedance coverage can be achieved with the output terminated either with an open or a short circuit (reflection mode). 


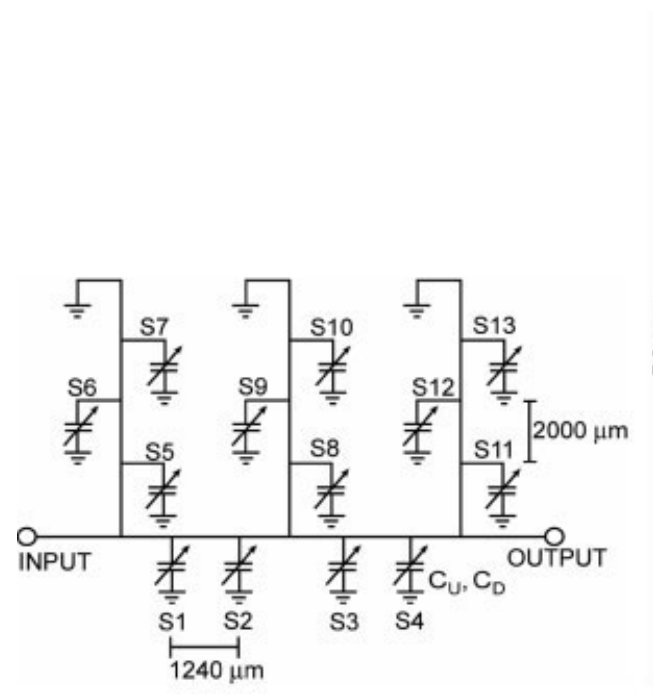

(a)

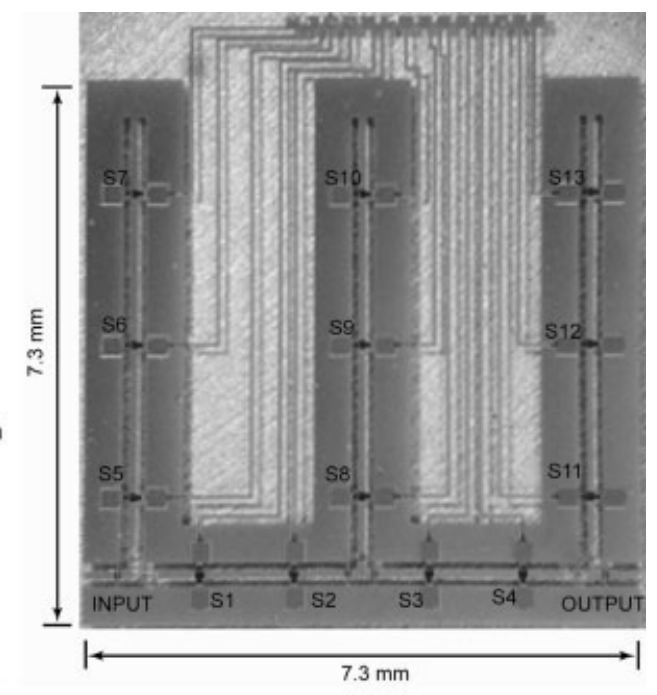

(b)

Figure 5. (a) Circuit diagram and (b) picture of the 6-20 GHz reconfigurable triple-stub RF MEMS impedance tuner with 13-switched MEMS capacitors (S1-S13). Note that two-switched capacitors are used between the stubs and the stubs are short circuited.

\section{Double-Stub Tuner with 11-Switched Capacitors}

The measured (160) and simulated (2048) impedance points for the double-stub tuner are shown in Figure 14 at $4-30 \mathrm{GHz}$. The impedance coverage of the double-stub tuner is not as wide as the impedance coverage of the triple-stub tuners at $6-20 \mathrm{GHz}$, but on the other hand, it is much better above 20 GHz. Notice that the impedance coverage at $6 \mathrm{GHz}$

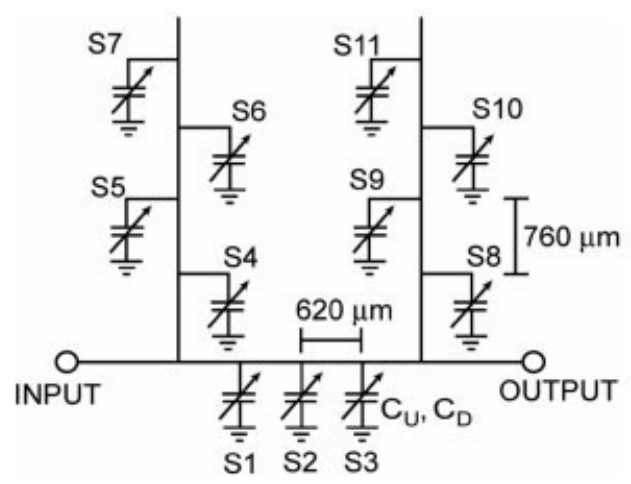

(a) is very small and this is because of the value of the switched capacitors and a resonant phenomena which is occurring at $6 \mathrm{GHz}$ due to the size of the double-stub tuner (this is not observed at 4 or at 8 $\mathrm{GHz}$ ). Our simulations clearly indicate that this can be mitigated by changing the values of the switched capacitor to be $C_{\mathrm{U}}=50 \mathrm{fF}$ and $C_{\mathrm{D}}=750 \mathrm{fF}$, but at the expense of a reduction in the tuning range to 18 $\mathrm{GHz}$.

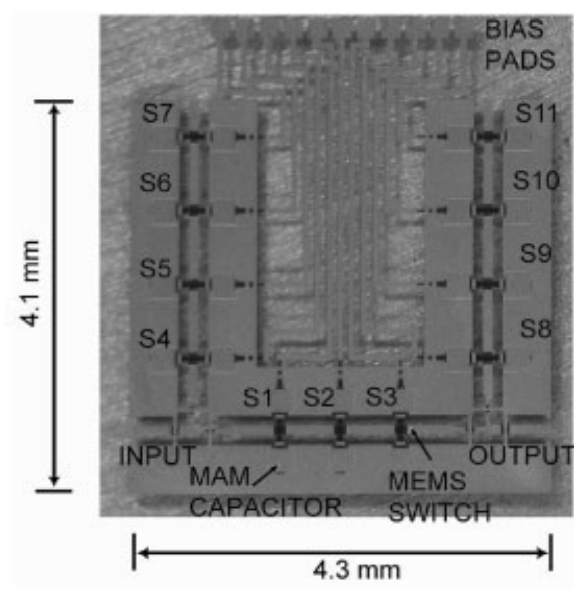

(b)

Figure 6. (a) Circuit diagram and (b) picture of the 4-30 GHz double-stub RF MEMS impedance tuner with 11-switched MEMS capacitors (S1-S11). Notice that three-switched capacitors are used between the stubs, and that the stubs are open circuited. 


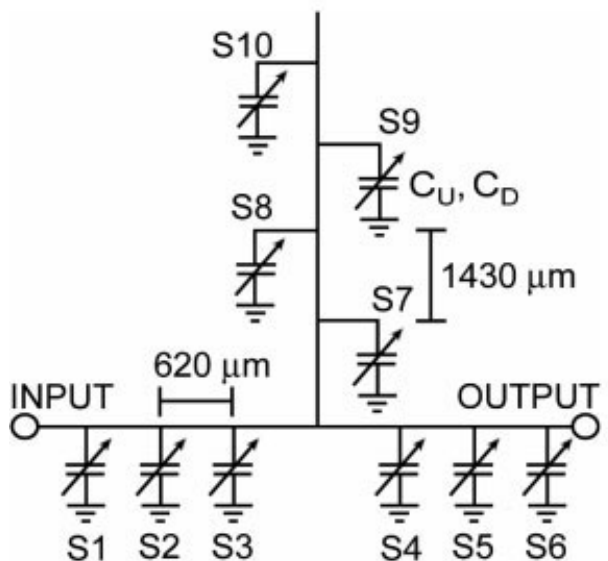

(a)

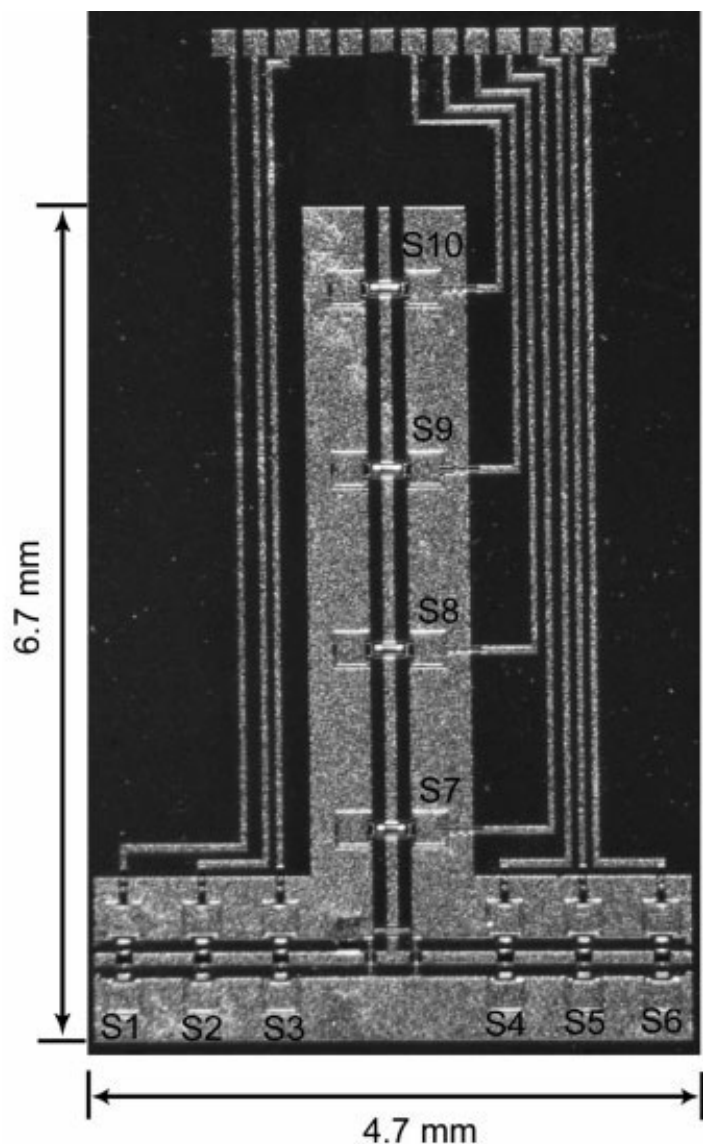

(b)

Figure 7. (a) Circuit diagram and (b) picture of the 6-25 GHz single-stub RF MEMS impedance tuner with 10-switched MEMS capacitors (S1-S10). Notice that three-switched capacitors are placed both before and after the stub.

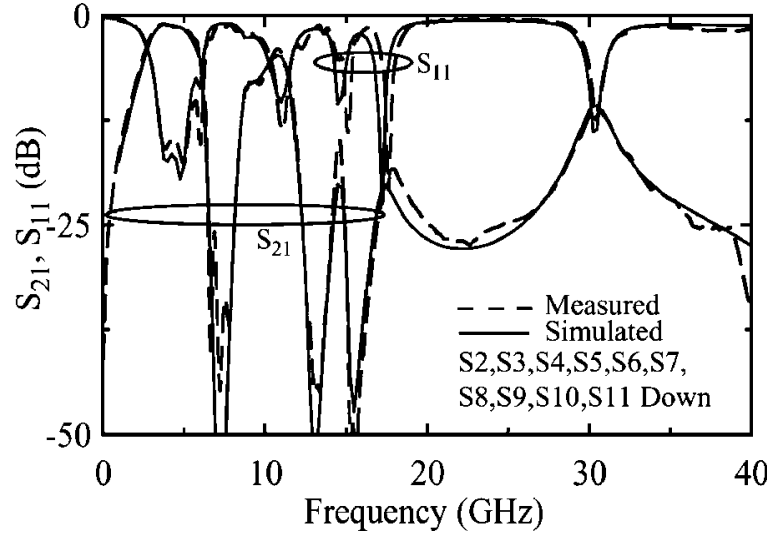

Figure 8. Measured and simulated $S$-parameters for the triple-stub tuner of Figure 4 with 11 switches, when switches S2, S3, S4, S5, S6, S7, S8, S9, S10, and S11 are in the down-state.

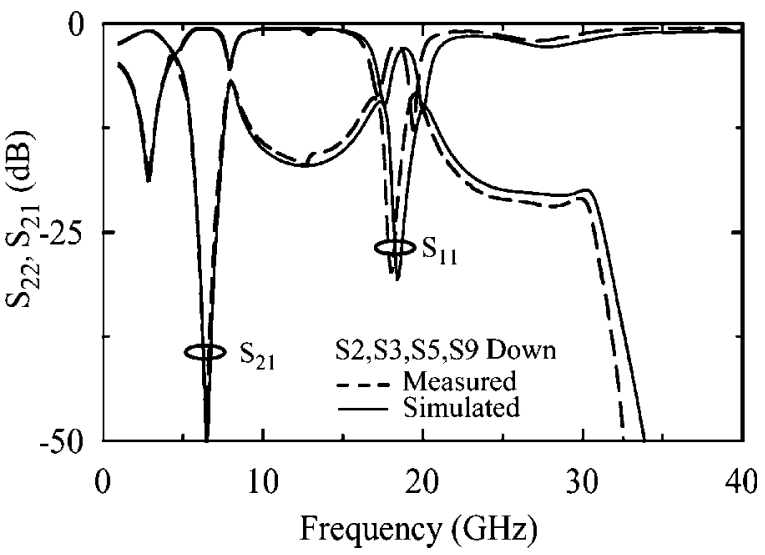

Figure 9. Measured and simulated $S$-parameters for the double-stub tuner of Figure 6 with 11 switches, when switches S2, S3, S5, and S9 are in the down-state. 


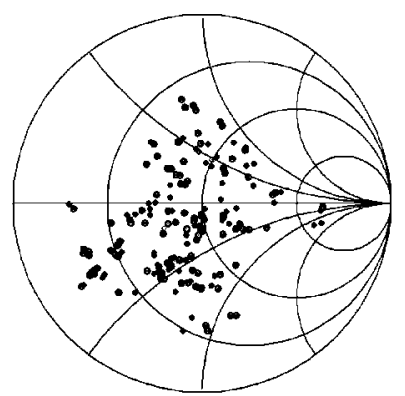

(a) Measured $6 \mathrm{GHz}$

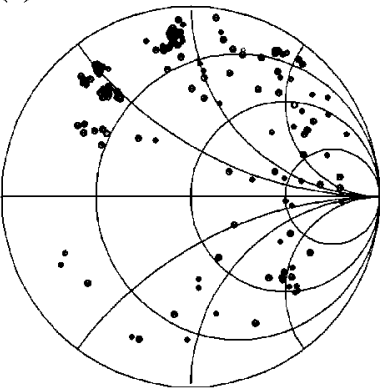

(c) Measured $16 \mathrm{GHz}$

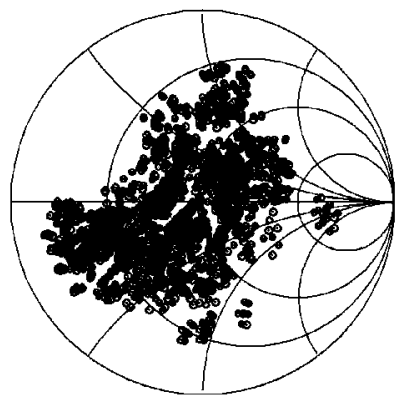

Simulated $6 \mathrm{GHz}$

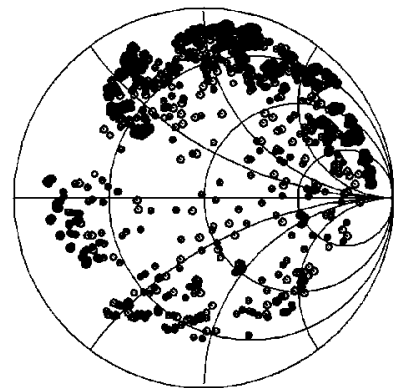

Simulated $16 \mathrm{GHz}$

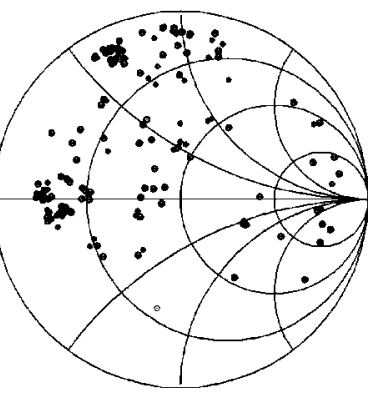

(b) Measured $12 \mathrm{GHz}$

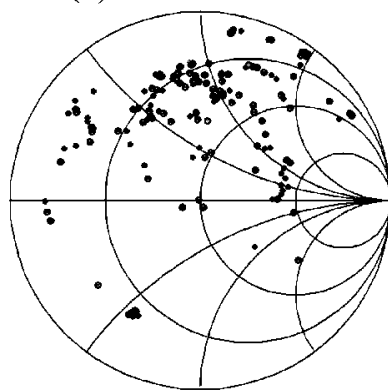

(d) Measured $20 \mathrm{GHz}$

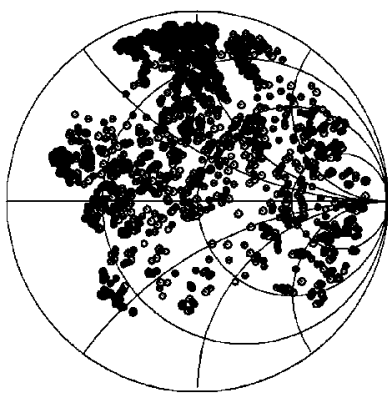

Simulated $12 \mathrm{GHz}$

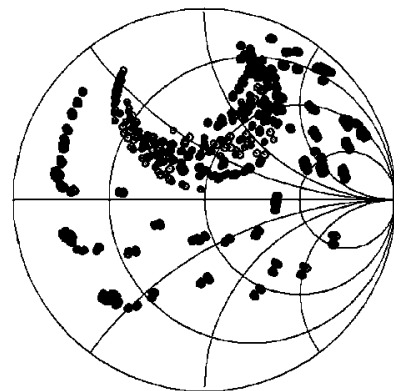

Simulated $20 \mathrm{GHz}$

Figure 10. (a)-(d) Measured (160 points) and simulated (2048 points) impedance coverage of the triple-stub tuner with 11-switched capacitors.

Figure 15 shows that even with the double-stub topology and an open-circuit termination at the output (reflection mode), it is possible to achieve as good impedance coverage as with the triple-stub tuners over a wide frequency range.

\section{Single-Stub Tuner with 10-Switched Capacitors}

Measured (90 points) and simulated (1024 points) impedance coverage of the single-stub tuner with an open circuited is presented in Figure 16 at 6-20 GHz. The single-stub tuner does not have the frequency bandwidth of the triple-stub design showing only good impedance coverage between 10 and $20 \mathrm{GHz}$.
Still, these are excellent results from a single-stub design, and is because of the variable impedance and electrical-length loading of the switched capacitors that are not only used in the stub, but also in the t-line before and after the stub. A single-stub tuner with a short circuited stub was also realized. It has as good impedance coverage as with the open circuited singlestub tuner. Our simulations indicate that the singlestub tuner with a $50 \Omega$ load can be improved by using switched capacitors having a higher capacitance ratio with $C_{\mathrm{U}}=50 \mathrm{fF}$ and $C_{\mathrm{D}}=800 \mathrm{fF}$. It will be seen in Section $\mathrm{V}$ that the single-stub tuner results in the lowest loss matching network out of all the cases presented above (for power amplifier applications).

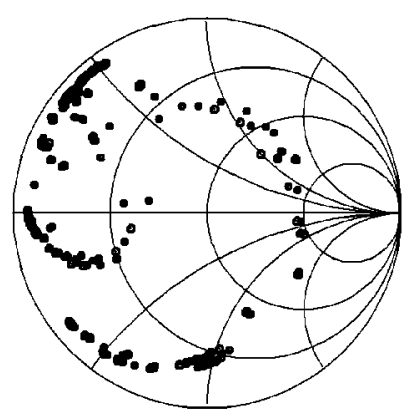

Simulated $6 \mathrm{GHz}$

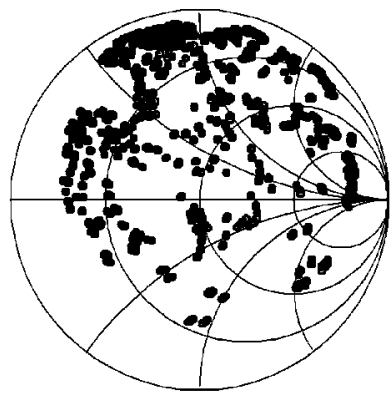

Simulated $10 \mathrm{GHz}$

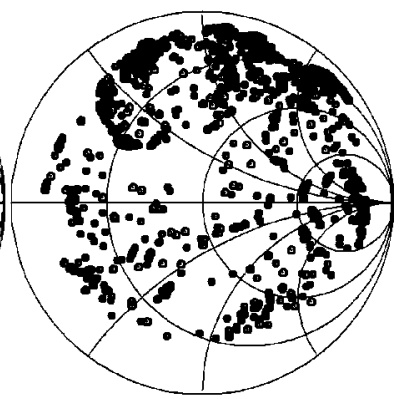

Simulated $16 \mathrm{GHz}$

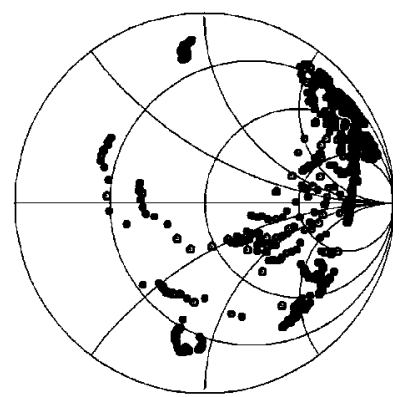

Simulated $24 \mathrm{GHz}$

Figure 11. Simulated (2048 points) impedance coverage of the triple-stub tuner when the output terminated with an open circuit. Similar results are achieved for a short-circuit termination. 


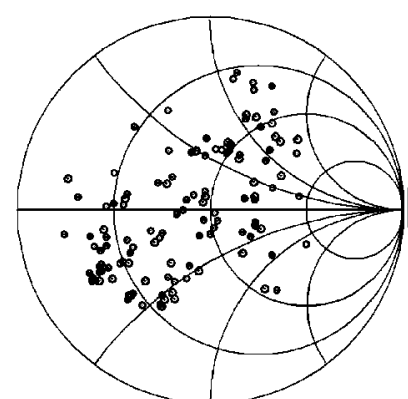

(a) Measured $6 \mathrm{GHz}$

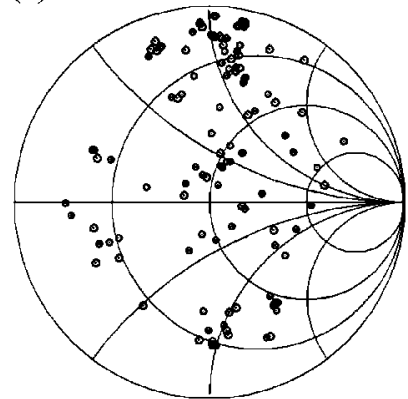

(c) Measured $16 \mathrm{GHz}$

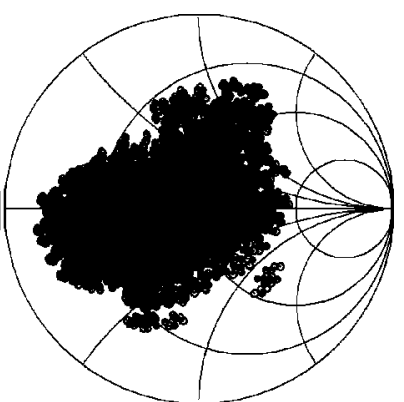

Simulated $6 \mathrm{GHz}$

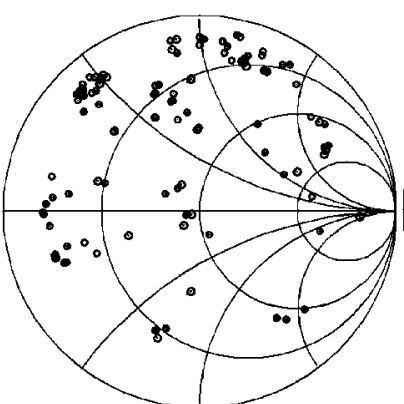

(b) Measured $12 \mathrm{GHz}$

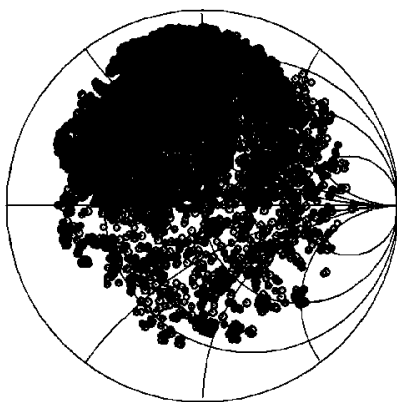

Simulated $12 \mathrm{GHz}$

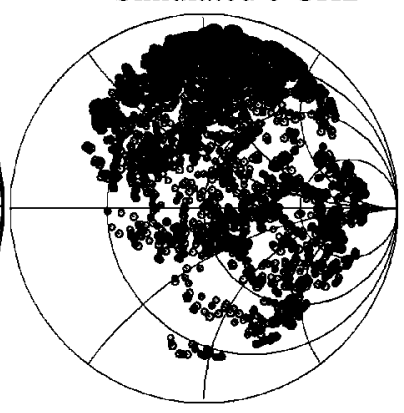

Simulated $16 \mathrm{GHz}$

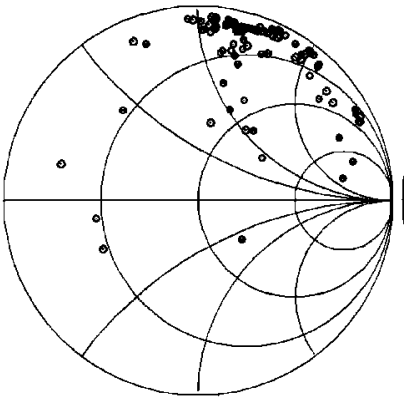

(d) Measured $20 \mathrm{GHz}$

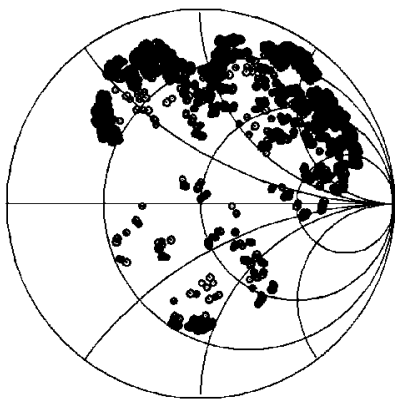

Simulated $20 \mathrm{GHz}$

Figure 12. (a)-(d) Measured (160 points) and simulated (8192 points) impedance coverage of the triple-stub tuner with 13 -switched capacitors with a $50 \Omega$ load.

Finally, if the network is terminated with an open or short circuit (reflection mode), one can obtain a very good impedance coverage at 6-24 $\mathrm{GHz}$ (Fig. 17).

\section{CASE STUDY: MATCHING OF A $20 \Omega$ LOAD TO $50 \Omega$}

The circuit model developed above can be used for analyzing different matching conditions. A $20 \Omega$ load was matched to $50 \Omega$ with the triple-, double-, and single-stub tuners at 4-20 GHz, and different switch combinations were chosen to achieve an impedance match better than $-19 \mathrm{~dB}$ at different frequencies. Figure 18 shows the case of the single-stub tuner, where the loss is defined as $1-\left|S_{11}\right|^{2}-\left|S_{21}\right|^{2}$ and includes the ohmic loss in the t-line and bridges, and radiation loss. The single-stub tuner is well suited for matching applications up to $16 \mathrm{GHz}$ with a loss of $0.1-0.2$ (90-80\% efficient which is $0.5-1 \mathrm{~dB}$ of loss). However, the loss is quite high in the triple- and double-stub tuners at 6-20 $\mathrm{GHz}(-2 \mathrm{~dB}$ loss) and is not shown. The reason is that these networks are quite large and include two or three T-junctions. Therefore, double- and triple-stub tuners are better suited for noise parameter and load-pull measurement applications.

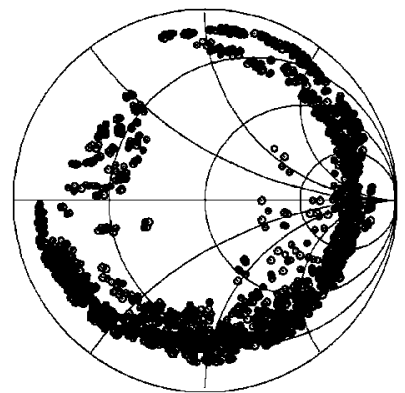

Simulated $6 \mathrm{GHz}$

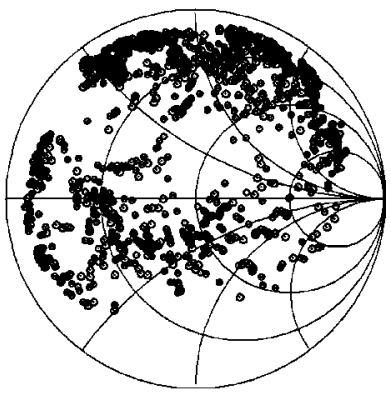

Simulated $10 \mathrm{GHz}$

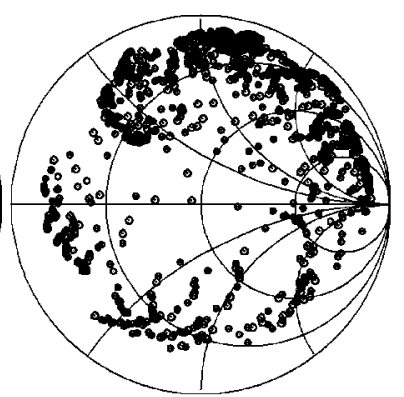

Simulated $16 \mathrm{GHz}$

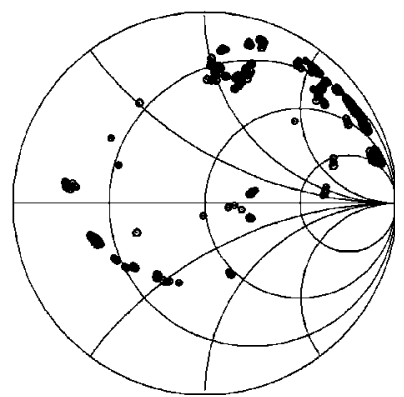

Simulated $24 \mathrm{GHz}$

Figure 13. Simulated (8192 points) impedance coverage of the triple-stub tuner with 13switched capacitors when the output is terminated with an open circuit (reflection mode). Similar results are achieved for a short-circuit termination. 


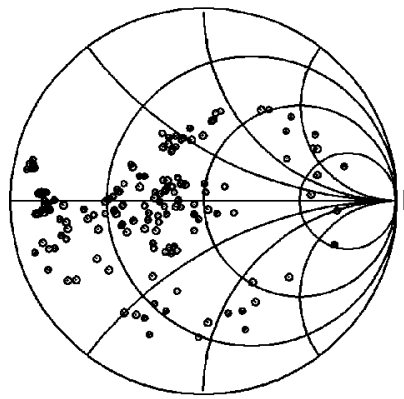

(a) Measured $4.1 \mathrm{GHz}$

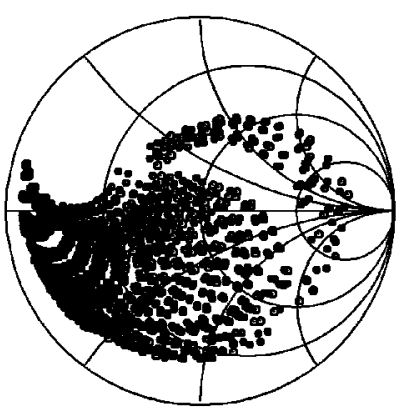

Simulated $4.1 \mathrm{GHz}$

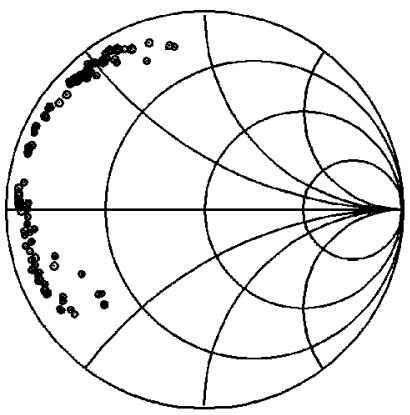

(b) Measured $6.1 \mathrm{GHz}$

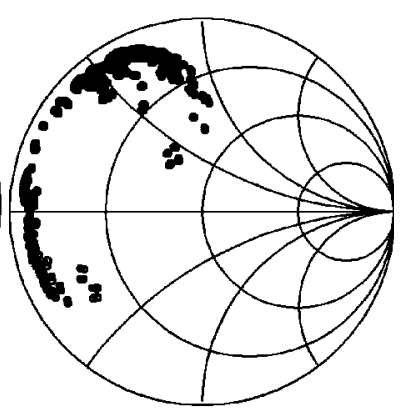

Simulated $6.1 \mathrm{GHz}$

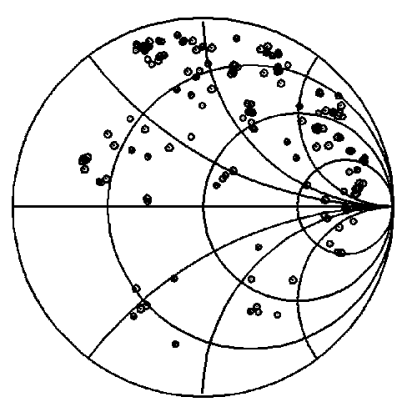

(c) Measured $16.2 \mathrm{GHz}$ Simulated $16.2 \mathrm{GHz}$

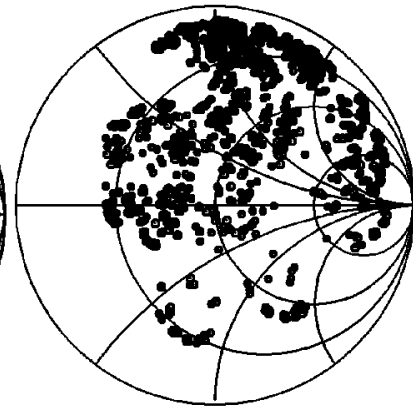

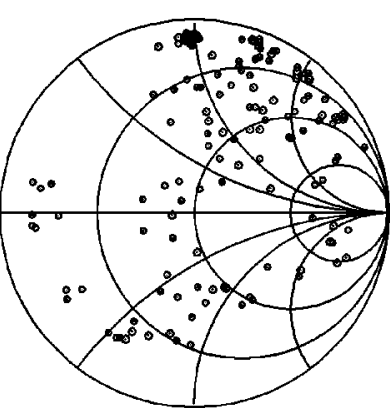

(d) Measured $20.2 \mathrm{GHz}$

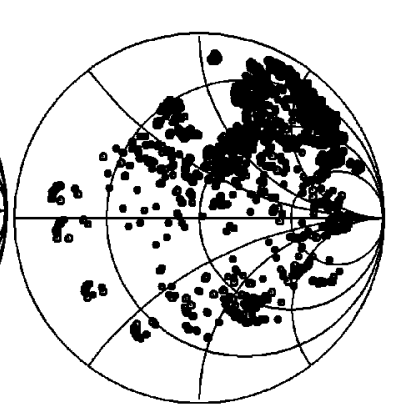

Simulated $20.2 \mathrm{GHz}$

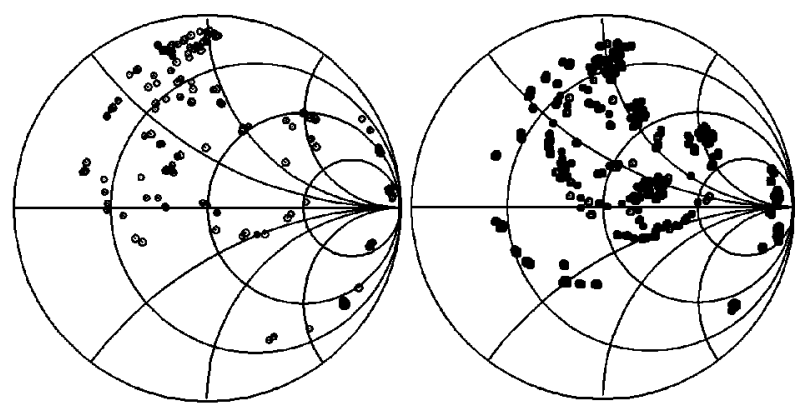

(e) Measured $32.3 \mathrm{GHz}$ Simulated $32.3 \mathrm{GHz}$

Figure 14. (a)-(f) Measured (160 points) and simulated (2048 points) impedance coverage of the double-stub tuner with 11-switched capacitors with a $50 \Omega$ load.

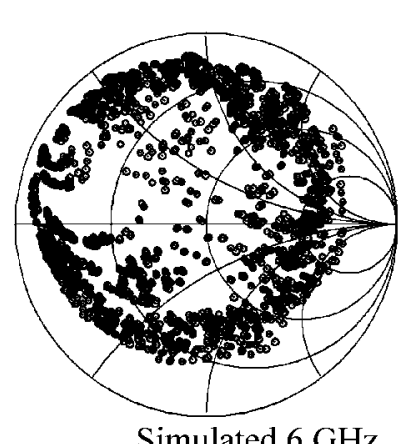

Simulated $6 \mathrm{GHz}$

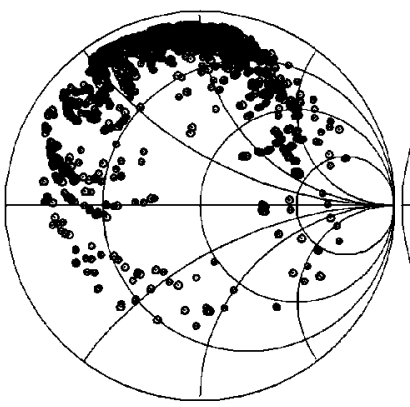

Simulated $10 \mathrm{GHz}$

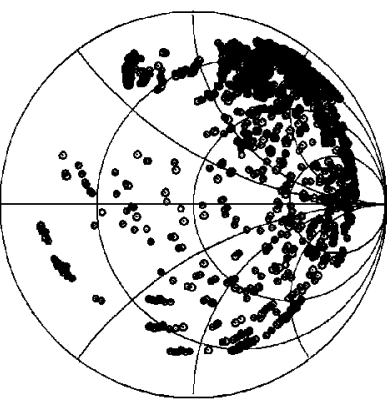

Simulated $20 \mathrm{GHz}$

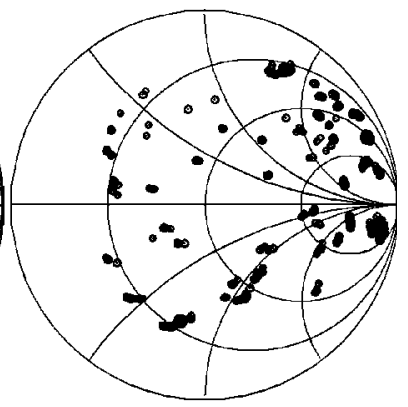

Simulated $30 \mathrm{GHz}$

Figure 15. Simulated (2048 points) impedance coverage of the double-stub tuner when the output terminated with an open circuit (reflection mode). The impedance coverage is the same at $10-30 \mathrm{GHz}$ for a short circuit termination and with a slightly reduced coverage at $6 \mathrm{GHz}$. 


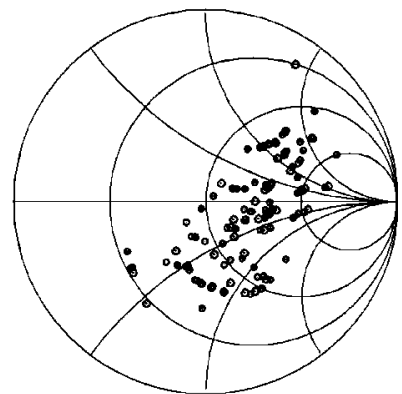

a) Measured $6 \mathrm{GHz}$

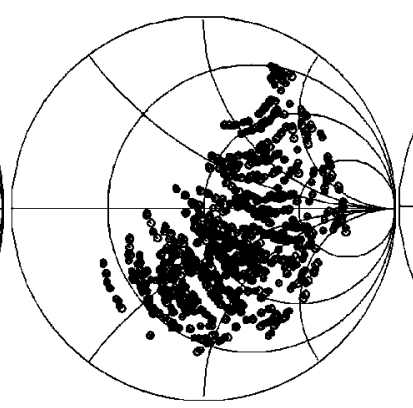

Simulated $6 \mathrm{GHz}$

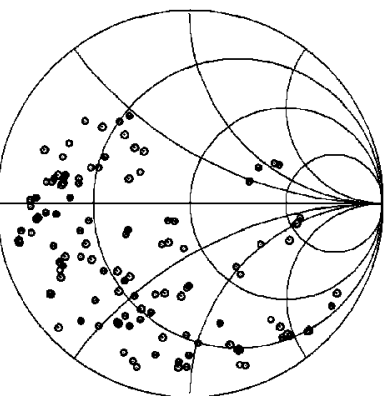

(b) Measured $12 \mathrm{GHz}$

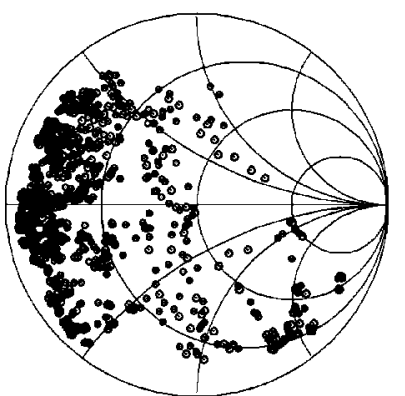

Simulated $12 \mathrm{GHz}$

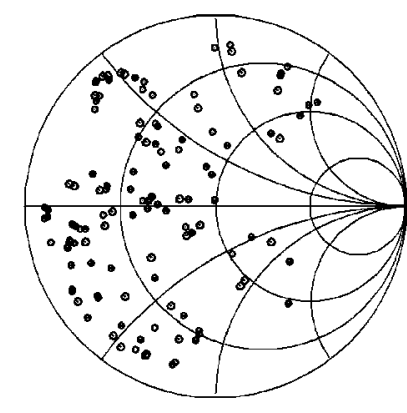

(c) Measured $16 \mathrm{GHz}$

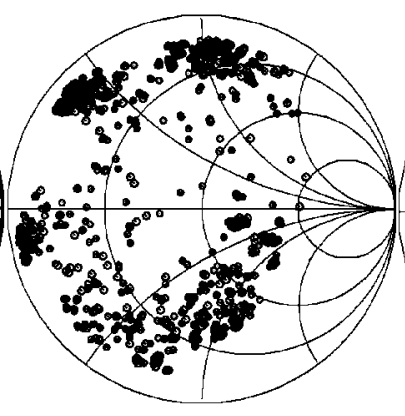

Simulated $16 \mathrm{GHz}$

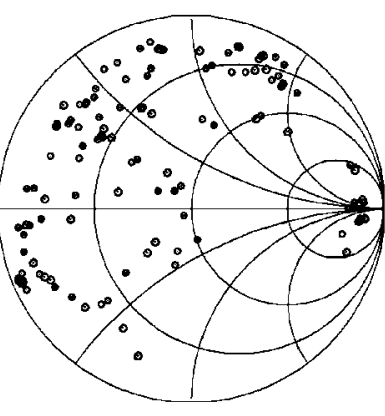

(d) Measured $20 \mathrm{GHz}$

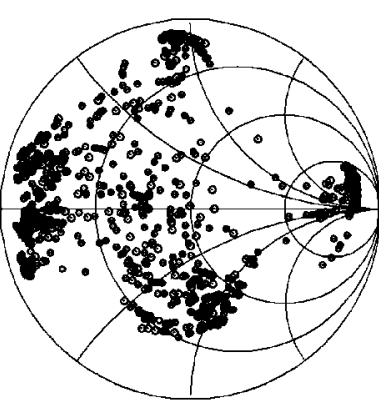

Simulated $20 \mathrm{GHz}$

Figure 16. (a)-(d) Measured (90 points) and simulated (1024 points) impedance coverage of the single-stub tuner with a $50 \Omega$ load.

\section{MEASURED $\left|\Gamma_{\text {MAX }}\right|$}

A figure of merit for impedance tuners is the maximum achievable reflection coefficient, $\left|\Gamma_{\mathrm{MAX}}\right|$, and the measured $\left|\Gamma_{\text {MAX }}\right|$ values for the tuners are shown in Table III (for the 90-160 points out of 1024-8192 possible). These measurements show that the double-stub tuner design with threeswitched capacitors between the stubs results in a measured $\left|\Gamma_{\text {MAX }}\right|>0.9$ for the whole frequency band, and the best measured $\left|\Gamma_{\text {MAX }}\right|$ is 0.99 at $30 \mathrm{GHz}$, which is equal to VSWR of 199 . The measured $\left|\Gamma_{\text {MAX }}\right|$ values are comparable with previously published integrated impedance tuners. Some notable results were: A VSWR of 6 at 27 $\mathrm{GHz}$ [4], a VSWR of 12.3 at $27 \mathrm{GHz}$ [5], a VSWR of 32.3 at $30 \mathrm{GHz}$ [6], and a VSWR of 99 at 20 $\mathrm{GHz}$ [7]. However, all of the tuners in [4-7] were quite narrowband as opposed to the wideband designs presented here.

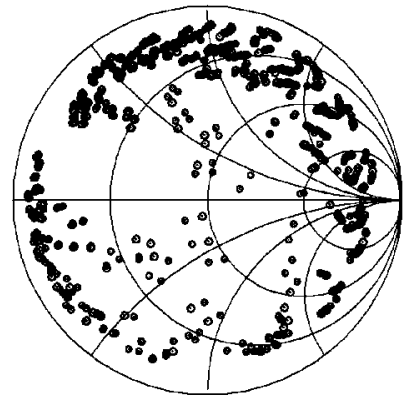

Simulated $6 \mathrm{GHz}$

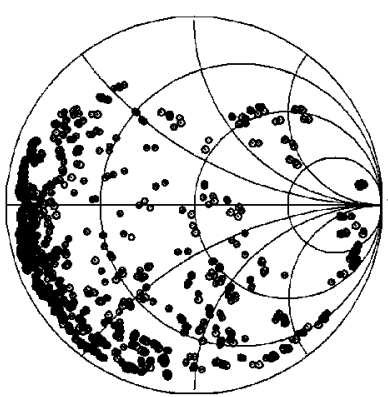

Simulated $10 \mathrm{GHz}$

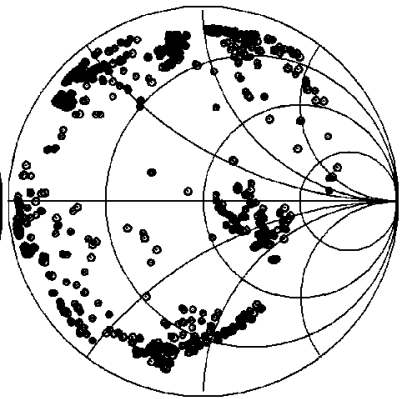

Simulated $16 \mathrm{GHz}$

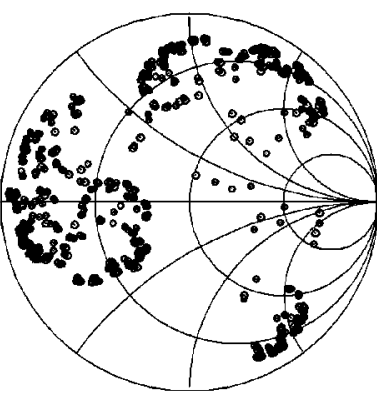

Simulated $24 \mathrm{GHz}$

Figure 17. Simulated (1024 points) impedance coverage of the single-stub tuner when the output terminated with an open circuit (reflection mode). The impedance coverage is the same at $10-30 \mathrm{GHz}$ for a short circuit termination but results in reduced coverage at $6 \mathrm{GHz}$. 


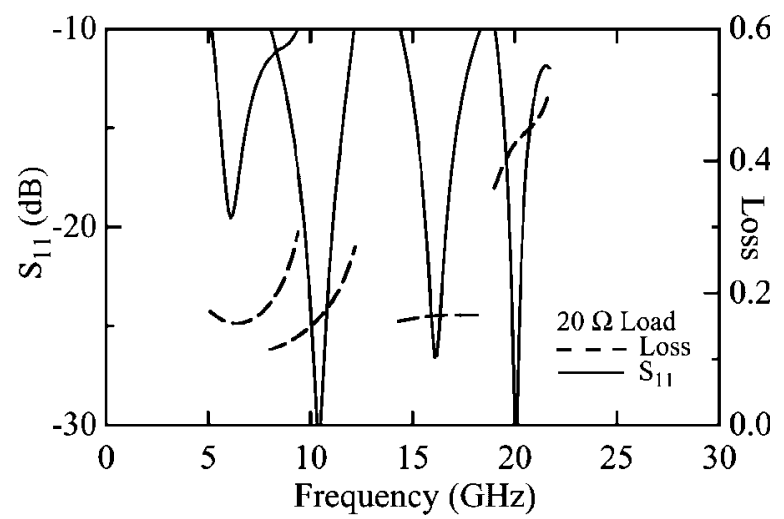

Figure 18. Simulated input reflection coefficient and loss of the single-stub tuner with 10 -switched capacitors at $6,10,16$, and $20 \mathrm{GHz}$ with a $20 \Omega$ load matched to 50 $\Omega$. Simulations were done based on the circuit model (which agrees very well with measurements). Switches S3, S4, S5, S7, S9, and S10 were down when matching at $6 \mathrm{GHz}, \mathrm{S} 5$ and $\mathrm{S} 10$ at $10 \mathrm{GHz}, \mathrm{S} 8$ and $\mathrm{S} 10$ at $16 \mathrm{GHz}$, and S4, S5, and S8 at $20 \mathrm{GHz}$.

\section{INTERMODULATION MEASUREMENTS}

The intermodulation analysis of MEMS switches and varactors is presented in Ref 15 and they show that MEMS-based circuits generate insignificant amount of intermodulation products, especially if the frequency difference between the two RF signals $(\Delta f)$ is higher than the mechanical resonant frequency of the bridge. The intermodulation measurements of the impedance tuners were carried out with the measurement set-up shown in Figure 19, and the circuits were terminated with either a $50 \Omega$ load or with a short circuit. In the case of the short circuit condition, the generated intermodulation signals (IM3 products) were measured at the input port using a circulator.

TABLE III. Measured $\left|\Gamma_{\text {MAX }}\right|$ for the Different

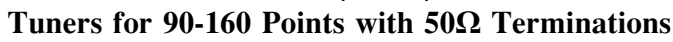

\begin{tabular}{ccccc}
\hline & \multicolumn{4}{c}{$\left|\Gamma_{\text {MAX }}\right|$} \\
\cline { 2 - 5 } $\begin{array}{l}\text { Frequency } \\
(\mathrm{GHz})\end{array}$ & $\begin{array}{c}\text { Triple- } \\
\text { Stub 11 } \\
\text { Switches }\end{array}$ & $\begin{array}{c}\text { Triple- } \\
\text { Stub 13 } \\
\text { Switches }\end{array}$ & $\begin{array}{c}\text { Double- } \\
\text { Stub 11 } \\
\text { Switches }\end{array}$ & $\begin{array}{c}\text { Single- } \\
\text { Stub 10 } \\
\text { Switches }\end{array}$ \\
\hline 6 & 0.77 & 0.77 & 0.95 & 0.86 \\
8 & 0.92 & 0.92 & 0.94 & 0.69 \\
12 & 0.92 & 0.92 & 0.91 & 0.93 \\
16 & 0.95 & 0.95 & 0.93 & 0.91 \\
20 & 0.96 & 0.97 & 0.96 & 0.97 \\
30 & 0.95 & 0.97 & 0.99 & 0.98 \\
\hline
\end{tabular}

Higher $\left|\Gamma_{\mathrm{MAX}}\right|$ could be achieved if more measurements points were taken

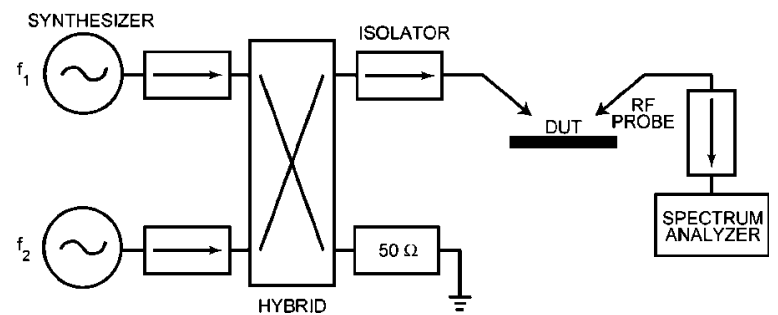

Figure 19. Schematic of the intermodulation measurement setup.

The triple-stub tuner with 11-switched-capacitors was measured at 8 and $17 \mathrm{GHz}$, and the measurement IIP3 is $>35 \mathrm{dBm}$ for a $5 \mathrm{kHz}$ separation frequency, even under short circuit conditions (Fig. 20). Figure 20 also shows that the intermodulation products are higher at $17 \mathrm{GHz}$ than at $8 \mathrm{GHz}$ as predicted in Ref 15 . Also, the IIP3 increases as $(\Delta f)^{4}$, and therefore it can be expected to be $>+60 \mathrm{dBm}$ for a $\Delta f$ of $1 \mathrm{MHz}$. This is so low that it is simply unmeasurable in most experimental setups. These findings confirm the results of Ref 15.

\section{POWER HANDLING}

Power handling is not a critical issue if the tuners are used in noise parameter measurements. However, in load-pull measurements, power handling can be important especially if the tuners are used at the output port. As is well known [14], if a DC or an RF voltage is applied between the electrodes of a MEMS switch, the position of the switch changes since the electrostatic force is dependent on $V^{2}$, and this translates to $V_{\mathrm{rms}}^{2}$ for RF voltages. The MEMS switch is pulled down if $\left|V_{\text {rms }}\right|$ is equal or greater than the DC pulldown voltage of the switch. Another problem related

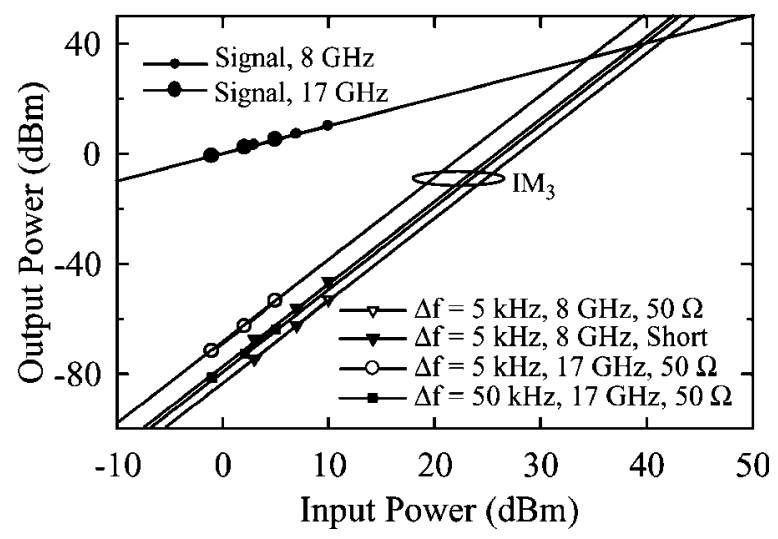

Figure 20. Measured third-order intermodulation of the triple-stub tuner with 11-switched capacitors at 8 and 17 $\mathrm{GHz}$, when all the switches were in the up-state. 


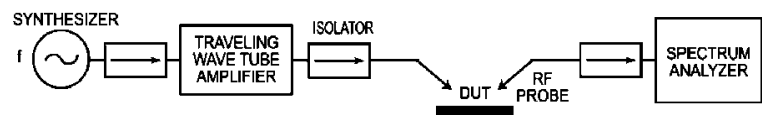

Figure 21. Schematic drawing of the power handling measurement setup.

to high RF power is the hold-down voltage in the down-state position $[15,16]$.

The power handling measurement setup is shown schematically in Figure 21, where isolators were used for achieving a $50 \Omega$ system at the source and the power meter. The power handling of the triplestub tuner with 11-switched capacitors was measured at 8 and $17.6 \mathrm{GHz}$ (Figure 22). The triple-stub tuner circuits can handle up to $23-24 \mathrm{dBm}$ RF power at 8$17 \mathrm{GHz}$ depending on the switch combination. This is enough for most transistors operating at this frequency band at the input port or as a tuner in noise parameter measurements, but this is not enough for an output port matching network.

The voltages and currents across the switched capacitors were simulated using Agilent ADS with $24 \mathrm{dBm}$ RF power (Fig. 23). The simulation predicts that switches $\mathrm{S} 1$ and $\mathrm{S} 2$ have the highest rms voltage $(5 \mathrm{~V})$. In this case, the pull-down voltage of the switches was closer to $10 \mathrm{~V}$ and a 5-6 V RF rms voltage will start to change the switch capacitance. However, this is not a complete solution, since it is assumed that the circuit is not changing, but as the bridge position and capacitance changes, the voltage distribution on the circuit changes, and may result in a higher voltage across S1 and S2. This means that a coupled microwave-circuit/mechanical-analysis solution is needed to find the behavior of the reconfigura-

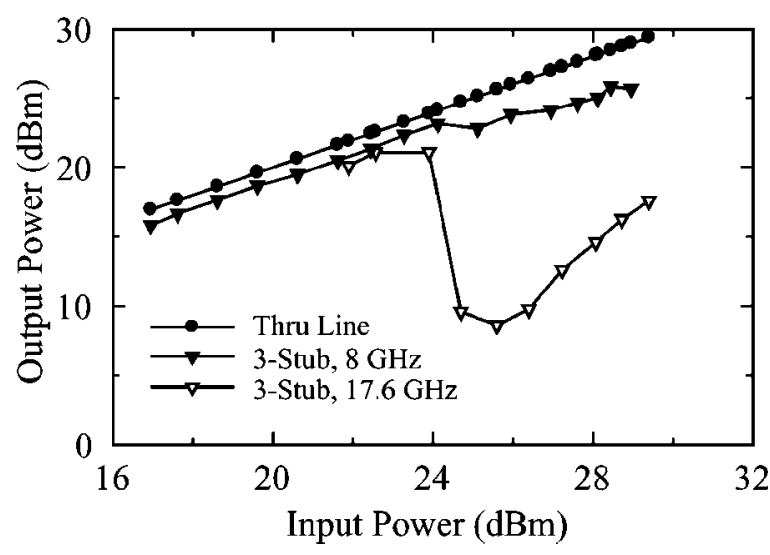

Figure 22. Measured power handling of the triple-stub tuner with 11 -switched capacitors at 8 and $17.6 \mathrm{GHz}$, when all of the switches were in the up-state position. In this case, a $24 \mathrm{dBm}$ power handling is observed. ble circuit in a dynamic fashion, and this is not done here.

For higher power handling, it is recommended that the MEMS switches are fabricated with a high pull-down voltage ( $30 \mathrm{~V}$ instead of $10-15 \mathrm{~V}$ ). This will increase the power handling by a factor of 4 to around $30 \mathrm{dBm}$. A potential problem which may arise from using $30-40 \mathrm{~V}$ bias voltages is the charging of the dielectric layer in the MEMS switch, but this is mitigated by the use of a thick SiN dielectric layer $(3500 \AA$ instead of the standard $1000 \AA$ ) since the design does not necessitate a large capacitance ratio. The currents in the switches are quite low, in both the up-state and down-state positions, and remain lower than $150 \mathrm{~mA}$ rms for virtually all switch combinations up to $30 \mathrm{dBm}$.

\section{CONCLUSIONS}

This article presented a whole set of impedance tuners for 6-24 GHz applications using single-, double-, and triple-stub topologies. The essential idea of the design is that switched capacitors with a relatively low capacitance ratio are used (and not switches), which results in a very large number of impedance combinations (1024-8192 different impedances for 10-13-switched capacitors). The switched capacitors were used for changing the electrical lengths and impedance of stubs and sections between the stubs. The measured impedance and frequency coverage of these tuners is the widest to-date from any integrated tuner at this frequency range. Also, these tuners can achieve a very high VSWR over a wide frequency range, and the double-stub tuner

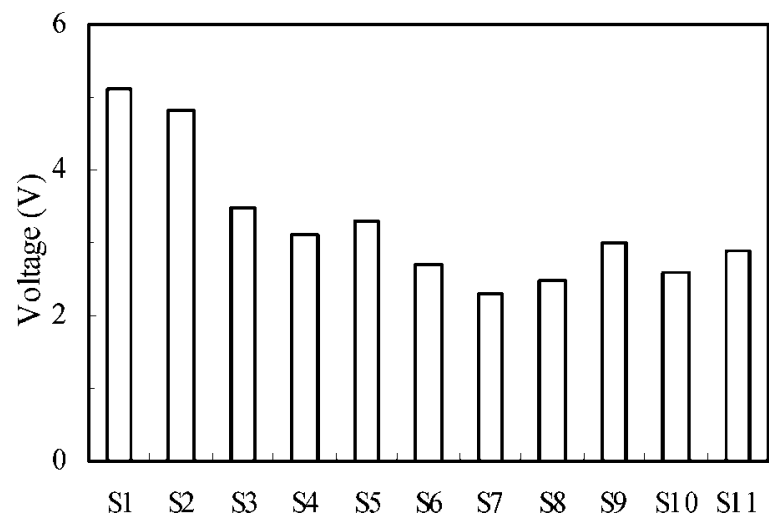

Figure 23. Simulated rms voltage across the switched capacitors in the triple-stub tuner with 11-switched capacitors at $17.6 \mathrm{GHz}$ with $24 \mathrm{dBm}$ input RF power. All switches were in the up-state in the simulations. 
resulted in a measured VSWR of 199 at $30 \mathrm{GHz}$. The areas of the single and double-stub tuners are small enough to be integrated inside on-wafer measurement probes to increase the measurement accuracy and automation in noise parameter or load-pull measurements systems. If the stub-based tuners are used as matching networks with amplifiers, the single-stub topology should be used to get the lowest loss. The tuners can be scaled up to $120 \mathrm{GHz}$ and this work has been presented in Refs 17-19.

\section{ACKNOWLEDGMENTS}

This work has been supported by the ESA/ESTEC contract no. 1655/95/NL/MV at MilliLab, VTT, and the DARPA IRFFE program at the University of Michigan.

\section{REFERENCES}

1. M. Kantanen, M. Lahdes, T. Vähä-Heikkilä, and J. Tuovinen, A wideband automated measurement system for on-wafer noise parameter measurements at 50-75 GHz, IEEE Trans Microwave Theory Tech 51 (2003), 1489-1495.

2. T. Vähä-Heikkilä, M. Lahdes, M. Kantanen, and J. Tuovinen, On-wafer noise parameter measurements at W-band, IEEE Trans Microwave Theory Tech 51 (2003), 1621-1628.

3. M. Pierpoint, R.D. D, and J.R. R, An automated measurement technique for measuring amplifier load-pull and verifying large-signal device models, IEEE MTTS International Microwave Symposium Digest, Vol. 86, Baltimore, Maryland, 1986, pp. 625-628.

4. W. Bischof, Variable impedance tuner for MMIC's, IEEE Microwave Guided Wave Lett 4 (1994), 172174.

5. C.E. McIntosh, R.D. Polland, and R.E. Miles, Novel MMIC source-impedance tuners for on-wafer microwave noise-parameter measurements, IEEE Trans Microwave Theory Tech 47 (1999), 125-131.

6. H.-T. Kim, S. Jung, K. Kang, J.-H. Park, Y.-K. Kim, and Y. Kwon, Low-loss analog and digital micromachined impedance tuners at the Ka-band, IEEE Trans Microwave Theory Tech 49 (2001), 2394-2400.

7. J. Papapolymerou, K.L. L, C.L. L, A. Malczewski, and J. Kleber, Reconfigurable double-stub tuners using
MEMS switches for intelligent RF front-ends, IEEE Trans Microwave Theory Tech 51 (2003), 271-278.

8. R.E. Collin, Foundations for microwave engineering, 2nd edition, McGraw-Hill, New York, 1992.

9. T. Vähä-Heikkilä, J. Varis, J. Tuovinen, and G.M. Rebeiz, A reconfigurable 6-20 GHz RF MEMS impedance tuner, IEEE MTT-S International Microwave Symposium Digest, Forth Worth, TX, USA, 2004, pp. 29-732.

10. T. Vähä-Heikkilä and G.M. Rebeiz, A $20-50 \mathrm{GHz}$ reconfigurable matching network for power amplifier applications, IEEE MTT-S International Microwave Symposium Digest, Forth Worth, TX, USA, 2004, pp. 17-721.

11. T. Vähä-Heikkilä and G.M. Rebeiz, A 4-18 GHz reconfigurable RF MEMS matching network for power amplifier applications, Int J RF Microwave Comput-Aid Eng 14 (2004), 356-372.

12. Q. Shen and N.S. Barker, A reconfigurable RF MEMS based double slug impedance tuner, Proceedings of the 35th European Microwave Conference, Paris, France, 2005, pp. 537-540.

13. J.B. Rizk, W-band RF MEMS switches, phase shifters and antennas, Ph.D. Dissertation, Department of Electrical Engineering University of Michigan at Ann Arbor, MI, 2003.

14. S. Van den Bosch and L. Martens, Improved impedance-pattern generation for automatic noise-parameter determination, IEEE Trans Microwave Theory Tech 46 (1998), 1673-1678.

15. L. Dussopt and G.M. Rebeiz, Intermodulation distortion and power handling in RF MEMS switches, varactors and tunable filters, IEEE Trans Microwave Theory Tech 51 (2003), 1247-1256.

16. G.M. Rebeiz, RF MEMS: Theory, design, and technology, Wiley, New York, 2003.

17. T. Vähä-Heikkilä, J. Varis, J. Tuovinen, and G.M. Rebeiz, A 20-50 GHz RF MEMS single-stub impedance tuner, IEEE Microwave Wireless Compon Lett 15 (2005), 205-207.

18. T. Vähä-Heikkilä, J. Varis, J. Tuovinen, and G.M. Rebeiz, A V-band single-stub RF MEMS impedance tuner, Proceedings of the 34th European Microwave Conference, Amsterdam, Netherlands, 2004), pp. 13011304.

19. T. Vähä-Heikkilä, J. Varis, J. Tuovinen, and G.M. Rebeiz, W-band RF MEMS double- and triple-stub impedance tuners, IEEE MTT-S International Microwave Symposium 2005, Long Beach, CA, June 2005, pp. 923-926. 


\section{BIOGRAPHIES}

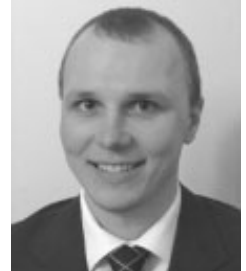

Tauno Vähä-Heikkilä received his B.Sc., M.Sc. and Lic. Tech. degrees in Physics from the University of Turku, Finland, in 2000, 2001, and 2005 resepctively, and Dr. Tech. degree in electrical engineering from the Helsinki University of Technology (TKK), Espoo, Finland, in 2006. He has worked as a Research Scientist since 2000 at the Millimetre Wave Laboratory of Finland-MilliLab at VTT. He was a visiting scholar at the University of Michigan, Ann Arbor, in 2002 and 2003, where he developed RF MEMS circuits for microwave and millimeter applications. His research interests include development of MEMS components and circuits for RF, microwave, and millimeter wave frequencies. He also develops measurement methods for microwave and millimeter wave on-wafer device characterization. $\mathrm{He}$ has authored or coauthored more than 30 scientific papers.

Koen Van Caekenberghe photo not available, ( $\left.S^{\prime} 99\right)$ was born in Vilvoorde, Belgium, in 1979. He received the M.Sc. degree in Electrical Engineering from the Katholieke Universiteit Leuven, Belgium, in July 2002, and is currently working toward the Ph.D. degree at the University of Michigan, Ann Arbor. Upon graduation in 2002, he joined Thales Naval, Hengelo, the Netherlands. During the summer of 2005, he was an intern at Bell Labs, Lucent Technologies, Murray Hill, NJ, where he measured SiGe RFIC transceivers for GSM and WCDMA application. His research interests are RF MEMS technology and microwave photonics for radar sensors.

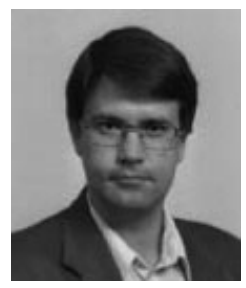

Jussi Varis received his M.Sc., Phil. Lic., and Ph.D. in Physics from University of Helsinki in 1993, 1994, and 1998 respectively. He has authored or coauthored 50 papers in international journals and conferences. Before joining VTT in 1999, Dr. Varis worked in the areas of infrared imaging and thermal nondestructive testing at the Department of Physics, University of Helsinki. Since 2001 he has participated in the development of the $70 \mathrm{GHz}$ receivers for the Low Frequency Instrument of the ESA Planck Surveyor as the Project Manager in the Millimetre Wave Laboratory of Finland-MilliLab. His current research interests include millimeter wave cryogenic circuits and measurements and microelectromechanical systems at millimeter waves. Dr. Varis leads the Millimetre Wave Technology team in the Circuits and Antennas knowledge center of VTT.

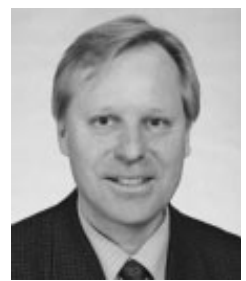

Jussi Tuovinen received the Dipl. Eng., Lic. Tech., and Dr. Tech. degrees in Electrical Engineering from the Helsinki University of Technology (HUT), Espoo, Finland, in 1986, 1989, and 1991, respectively. During the period 1986-1991 he worked as a Research Engineer at HUT Radio Laboratory, where he was involved with millimete-wave antenna testing for European Space Agency (ESA), quasi-optical measurements, and Gaussian beam theory. From 1991 to 1994 he was with the Five College Radio Astronomy Observatory at the University of Massachusetts, Amherst, as a Senior Postdoc, where he studied holographic test methods for large telescopes and developed frequency multipliers up to $1 \mathrm{THz}$. From 1994 to 1995 he was a Project Manager at HUT Radio Laboratory, involved with hologram CATR and $119 \mathrm{GHz}$ receiver development for the Odin-satellite. From 1995 to 2004 he was the Director of the Millimetre Wave Laboratory of Finland-MilliLab, ESA External Laboratory. He is a coinvestigator and heading development of $70 \mathrm{GHz}$ receivers for the Low Frequency Instrument of the ESA Planck Mission. His research activities also include development of methods for on-wafer testing of integrated circuits and components as well as imaging systems and MEMS at millimeter wave. Since 1999, he has been a Research Professor at VTT, Espoo Finland. In 2004-05, he was the Research Director of VTT Information Technology. Presently he is Vice President, R\&D, Microtechnologies and Sensors at VTT. Dr. Tuovinen has authored or coauthored over 150 scientific papers. Dr. Tuovinen received ESA Fellowships for multiplier work at the University of Massachusetts in 1992 and again in 1993. In 2001-2002, he worked as a Visiting Researcher at the University of Hawaii at Manoa, where he developed multipath communications methods using retrodirective antennas. $\mathrm{He}$ is a past secretary of the Finnish National Committee of COSPAR (Committee on Space Research) and the IEEE Finland Section. He was also the Executive Secretary of the Local Organizing Committee of the 27th Plenary Meeting of COSPAR held in 1988. In 1998, Dr. Tuovinen was the Co-Chairman of the 2nd ESA Workshop on Millimetre Wave Technology and Applications. Dr. Tuovinen has also served as a Chairman of the IEEE MTT/AP Finland Chapter. In 2003, he served as the Chairman of the 3rd ESA Workshop on Millimetre Wave Technology and Applications.

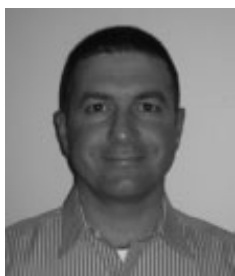

Gabriel M. Rebeiz (Fellow, IEEE) earned his Ph.D. degree in Electrical Engineering from the California Institute of Technology, Pasadena, and is a Full Professor of ECE at the University of California, San Diego. His research interests include applying microelectromechanical systems (MEMS) for the development of novel RF and microwave components and subsystems. He also leads a large effort in Si RFIC design for radar and communication systems, and in the development of millimeter-wave front-end electronics, planar antennas, imaging systems and phased-arrays. Prof. Rebeiz was the recipient of the National Science Foundation Presidential Young Investigator Award in April 1991, and the URSI International Isaac Koga Gold Medal Award in August 1993. At the University of Michigan, Ann Arbor, Prof. Rebeiz was selected by the students as the 1997-1998 Eta-Kappa$\mathrm{Nu}$ EECS Professor of the Year. In October 1998, he received the Amoco Foundation Teaching Award, given yearly to one or two faculty at the University of Michigan, for excellence in undergraduate teaching. Prof. Rebeiz is the corecipient, with Prof. Scott Barker, of the IEEE 2000 Microwave Prize. In 2003, he received the Outstanding Young Engineer Award of the IEEE MTT Society. Prof. Rebeiz is a Distinguished Lecturer for the IEEE MTT Society on RF MEMS, and is the author of the book RF MEMS: Theory, Design and Technology, Wiley 2003. 